\title{
POTENSI FESES TERNAK SAPI DALAM MENDUKUNG KEGIATAN PERTANIAN (Potential Cattle Feses in Support Agricultural Activity)
}

\author{
Irmayani $^{1}$, Yus riadi ${ }^{2}$, Arifuddin $^{3}$ \\ Universitas Muhammadiyah Parepare \\ ${ }^{2} E_{-}$Mail: yusry_ady@yahoo.co.id
}

\begin{abstract}
Enrekang has approximately 2000 dairy cows were spread across several districts. If the average of the dairy cows produce feces every day as much as $35 \mathrm{~kg}$, so the number of dairy cattle in the district waste Enrekang sebanyhak 70 tons / day. This fact shows the potential for waste is unbelievably big. The waste kepertingan if used for other sectors, such as agriculture, it will also create a promising organic farming. However, if waste is not utilized or dumped into the river or surrounding neighborhood residents, then a few years later would meet dairy cattle waste streams and neighborhoods. The method used for the libah memanfaatakan that u se animal feces as a medium for the cultivation of worms, to support activities of livestock cattle feces dimanfaatakan as biogas, then the waste from the biogas is used also as a medium for the cultivation of worms. The results of the activities acquired two flagship products, the first worm which farmed in parentheses obtained within two months of worms doubled the number of sires. Second, the benefits obtained by the former media cultivation of worms into compost. Stool processing technology that diverse is expected to improve the knowledge offarmers in processing the waste so it is not wasted. Processing of pliers berfareasi feces will increase public interest in managing rancher sector so as to create farming systems based Zero Waste.
\end{abstract}

Key Words : Potensi, Peternakan Sapi, Zero Waste

\section{PENDAHULUAN \\ Limbah peternakan khususnya sapi} memiliki banyak potensi. Potensi lembah di setiap daerah bermacam-macam serta bervareasi sesuai dengan komoditi yang di kelola. Kabupaten enrekang khususnya, salah satu daerah di sulawesi selatan ini memiliki potensi limbah sapi perah yang sangat melimpah. Sampai saai ini enrekang telah memiliki kurang lebih 2000 ekor sapi perah yang tersebar di beberapa kecamatan. Jika rata-rata satu ekor sapi perah menghasilkan feses setiap harinya sebanyak $35 \mathrm{~kg}$, jadi jumlah limbah ternak perah di kabupaten enrekang sebanyhak 70 ton/hari. Fakta ini menunjukkan potensi limbah sangan besar.

Menurut Dwiastuti (2014) mengemukakan potensi dan peran cacing tanah sangat bermanfaat terhadap kesuburan tanah yaitu untuk manfaat biologi berperan dalam mengubah bahan organik menjadi humus hal ini dilakukan melalui aktivitas cacingtanah dengan membawa bahan organik kebagian bawah tanah. Didalam liang cacing menghancurkan seresah dan mencernanya kemudian mencampurnya dengan tanah dan terbentuklah cast yang mengandung $40 \%$ humus. Dari aspek kimia bahan organik mati dicernaa oleh cacing bersama partikel tanah dan selanjutnya disekresikan dalam bentuk cast disimpan dipermukaan tanah. Secara alami cacing mencari makan di permukaan tanah, kelebihan cahaya dapat memaksa cacing bersembunyi sehingga konsumsi makan turun. Hal ini sesuai dengan sifatsifat biologis cacing tanah yaitu tidak tahan cahaya atau matahari langsung, hidup ditempat gelap, tidak tahan genangan air serta lebih aktif dimalam hari. Cacing tanah mendaur ulang (recycle) bahan organik dengan cara memakan bahan tanaman dan hewan yang mati, kotoran hewan dan organisme tanah yang lain. Dari aspek fisik cacing tanah 
mampu menjaga liang-liang didalam tanah dimana struktur tanahnya selalu dalam keadaan terbuka dan menciptakan kanal-kanal yang memungkinkan proses aerasi dan drainase.

Menurut Sugianto (2012), bahwa cacing tanah merupakan salah satu kelompok makrofauna yang memainkan peranan penting dalam berbagai proses fisika, kimia maupun biologi tanah. Hewan ini membuat liang dalam tanah sehingga meningkatkan porositas tanah. Hal ini membantu proses peresan air sehingga mengurangi aliran permukaan dan menurunkan risiko banjir. Selain itu hewan ini juga membantu proses dekomposisi bahan organik dan pelepasan hara ke dalam tanah, sehingga meningkatkan kesuburan tanah.

Kajian keuntungan yang diperoleh dengan membudidayakan cacing yaitu pertama, sekarang ini cacing banyak dimanfaatan untuk umpan untuk memancing. Kedua, cacing digunakan sebagai bahan obat untuk penyakit tipes, serta yang ketiga bekas budidaya cacing menjadi kompos yang sangat baik. Keuntungan tersebut yang menyebabkan kegiatan ini sangat tepat dilaksanakan pada masyarakat dalam memanfaatkan feses ternak yang selama ini kurang dimaksimalkan sebagai media budidaya cacing.

Hal tersebutlah yang menjadi potensi dalam bidang peternakan. Oleh karena itu, kita perlu melihat peluang-peluang dari produk-produk peternakan yang dapat dimanfaatkan. Salah satu peluang, yang dapat dimanfaatkan yaitu kotoron dan limbah urine sebagai bahan baku pembuatan pupuk kompos. Saat ini penggunaan pupuk organik makin meningkat sejalan dengan berkembangnya pertanian organik. Dengan sentuhan inovasi teknologi, peternak sudah bisa memperoleh hasil sebelum ternak itu dijual (kutipan dari Topngawi, 2013).

Tidak hanya media budidaya cacing, feses ternak sering pula diolah menjadi biogas dan pupuk organik. Berdasarkan hasil penelitian Yusriadi (2011), selain pupuk cair limbah ternak perah juga sangat cocok untuk pembuatan biogas. biogas merupakan energi yang dapat diperbaharui serta dapat dijadikan bahan bakar alternatif untuk menggantikan bahan bakar yang berasal dari fosil seperti minyak tanah dan gas alam. Di beberapa negara, biogas membawa keuntungan untuk kesehatan, sosial, lingkungan dan finansial. Dijelaskan lebih lanjut bahwa instalasi biogas adalah suatu penyediaan sumber energi desentralisasi yang sangat berguna. Contohnya di Tanzania biogas di hasilkan dari limbah kota dan industuri yang menghasilkan tenaga listrik dan pupuk. Jadi peternak dapat memperoleh dua keuntungan dari pengolahan limbah yaitu untuk energi dan untuk pupuk ciar.

Menurut Bambang (2013), bahwa Urine sapi yang selama ini dianggap limbah sebenarnya dapat dimanfaatkan menjadi pupuk cair yang kualitasnya dapat diandalkan untuk menggantikan pupuk kimia. Pupuk cair organik itu memiliki kandungan unsur hara yang lebih lengkap dibandingkan dengan pupuk kimia. Dengan pengolahan sederhana urine sapi dapat diubah menjadi pupuk cair yang nilainya lebih tinggi.

Potensi sektor peternakan bukan tanpa masalah, pengelola ternak pernah memiliki banyak masalah diantaranya:

a. Aspek Produksi

Produksi utama peternakan sapi perah yaitu

Susu. Susu diKabupaten Enrekang sampai 
sekarang ini diproduksi sebagai bahan dasar pembuatan dangke (makanan khas masyarakat Enrekang). Yang menjadi masalah di aspek ini yaitu masih kurangnya produksi susu setiap ekornya.

b. Aspek Manajemen

Kondisi peternakan di Kabupaten Enrekang sudah cukup baik, namun kondisinya masih memperihatinkan karena sistem perkandangan yang belum memadai dimana feses masih dibiarkan menumpuk disekitat kandang. Sistem pemberian pakan yang belum maksimal karena belum lengkapnya pakan tambahan untuk sapi perah sehingga menyebabkan produksi susu yang belum maksimal. Selain itu, metode memerah susu yang masih sederhana jadi memerlukan tenaga dan waktu yang cukup lama. Yang lebih menyedihkannya banyak peternak yang membuang limbahnya ke sungai.

c. Aspek Lingkungan

Feses dan irun yang dihasilkan ternak setiap harinya belum dimanfaatkan secara maksimal, sehingga mencemari lingkungan karena biasanya dibuang langsung ke sungai atau dibiarkan menumpuk. Belum adanya pengolahan limbah yang maksimal menyebabkan peternak membiarkan limbah ternaknya menumpuk begitu saja.

\section{TARGET DAN LUARAN}

\section{Target}

Pengolahan limbah peternakan yang masih kurang diminati peternak menjadi suatu tantangan yang harus dilalui sehingga menciptakan peternakan yang miliki mutu tinggi serta hasil dari kegiatan peternak berwujud nyata dalam kehidupan. Feses yang dijadikan media cacing diharapkan menjadi produk unggulan baru bagi peternak. Selain itu, dari proses tersebut diperoleh bekas cacing yang telah menjadi kompos. Oleh karena itu, terget utama pada kegiatan ini, yaitu:

1. Pemanfaatan secara maksimal limbah sapi perah berupa feses menjadi media budidaya cacing, sehingga tidak ada lagi limbah yang terbuang percuma setiap harinya.

2. Pembuatan reaktor Biogas untuk menciptaka energi terbaharukan yang dapat menggantikan bahan bakar minyak atau LPG

3. Pembuatan pupuk Organik

\section{Luaran}

Feser yang telah didaur ulang secara alamiah oleh cacing dapat menjadi peroduk yang bermutu tinggi dan mejadi produk sampingan yang dapat menambah penghasilan peternak dan keluarganya. Oleh karena luaran yang diharapkan pada kegiatan ini, diantaranya:

1. Lingkungan mejadi terjaga karena feses tidak terbuang dan mencemari lingkungan.

2. Adanya keuntungan tambahan yang diperoleh dari hasil penjualan cacing.

3. Meningkatkan pengetahuan, keterampilan serta pengalaman peternak melalui budidaya cacing.

\section{METODE DAN BAHAN}

\section{Proses Pemafaatan Feses sebagai Media Cacing.}

Feses ternak yang dihasilkan dari proses pencernaan ternak sapi dibiarkan selama satu hari, kemudian setelah itu dimasukkan dalam wadah 
yang berisi cacing yang telah diberi tanah. Hal ini bertujuan agar feses menjadi bahan makanan bagi cacing. Hasil penguraian dari cacing akan dibuang kembali dalam bentuk feses cacing, pada waktu tertentu, cacing sudah bisa dipanen, serta bekas dari $b=$ mida cacing diakan diambil menjadi kompos.

\section{Pembuatan Reaktor Biogas}

1. Mengolahan feses menjadi energi alternatif akan menggunakan teknologi biogas dari beton.

2. Biogas akan dibangun 2 (tiga) unit sehingga dapat digunakan sampai 10 kepala keluarga.

3. Proses produksi biogas dimulai dari pencamuran feses ternak dan air dengan perbandingan $1: 1$, dimana 1 liter feses dan 1 liter air lalu diaduk hingga merata. Feses yang telah tercampur dengan air kemudian dimasukkan ke dalam digester selanjutnya didiamkan selama 10 - 20 hari dalam keadaan hampa udara (anerob). Pada kondisi inilah terjadi reaksi dan interaksi antara bakteri metanogen dan non-metanogen serta bahan yang diumpankan ke dalam digester sebagai input. Ini adalah phisio-kimia yang kompleks dengan proses biologis yang melibatkan berbagai faktor dan tahapan bentuk.

\section{Proses Pembuatan Pupuk Organik}

Cara pengulahan urin menjadi pupuk cair sangatlah mudah, diantaranya semua bahan seperti urin, tetes tebu, EM4 dicampurkan didalam ember atau drum plastik, yang perlu dingat pengisian jangan sampai penuh. Lalu ditutup rapat dan didiamkan selama 3 minggu. Setiap hari 2 kali atau tiap pagi dan sore tutup dibuka untuk membuang gas yang dihasilkan atau boleh menggunakan aerator untuk mempercepat proses penguapan gas. Pupuk cair yang telah jadi, dapat langsung digunakan yaitu : 1 liter pupuk cair urine sapi dicampur 10 liter air lalu disemprotkan ke tanaman. Pabila pupuk cair urine sapi ini disimpan paling baik selama 12 hari dan harus tertutup rapat agar kadar nitrogen dan urine tidak banyak keluar

\section{HASIL DAN PEMBAHASAN}

\section{Pengolahan Feses sebagai Media Cacing}

1. Pemanfaatan feses ternak menjadi media budidaya cacing dilakukan dengan menggunakan feses yang telah dikeringkan. Untuk satu wadah diperlukan sebanyak $10 \mathrm{~kg}$ feses kering dengan indukan cacing sebanyak $2 \mathrm{~kg}$. Dalam waktu dua sampai dengan 3 minggu cacing mulai bertelur dan menhasilkan jumlah cacing dua kali lipat dari indukan sebelumnya. Setiap 3 minggu sekali dilakukan pemannenan dengan meisahkan cacing yang dewasa dengan anakan cacing.

2. Cacing dewasa dapat langsung dijual kepada pengepul yang biasanya dijadikan umpan ikan dapa saat memancing. Sedangkan anakan akan dipindahkan kewadah pembesaran dengan menggunakan media baru.

3. Untuk media sebelumnya, beaks cacing tersebut dapat digunakan menjadi kompos, yang digunakan baik pada tanaman hias maupun tanaman sayur-sayuran.

\section{Pengolahan Feses Menjadi BIOGAS}

Hasil pengamatan diketahui bahwa sebelum digunakan biogas peternak menggunakan tabung LPG ukuran $3 \mathrm{~kg}$ paling lama 1 minggu. Untuk ukuran 15 kg hanya digunakan kurang lebih 40 - 
50 hari. Namun setelah menggunakan biogas, dalam ssatu bulan peternak hanya membeli satu kali tabung LPG ukuran $3 \mathrm{~kg}$. tabel perbandingan penggunakan biogas dengan GAS LPG

Tabel 1. Penggunaan Biogas dibanding tabung LPG

\begin{tabular}{|l|l|l|}
\hline No & $\begin{array}{l}\text { Penggunaan } \\
\text { Tabung LPG }\end{array}$ & $\begin{array}{l}\text { Gambarang } \\
\text { Pengguaan Biogas }\end{array}$ \\
\hline 1 & $\begin{array}{l}\text { Tabung 3 kg hanya } \\
\text { bisa digunakan } \\
\text { kurang lebih 1 } \\
\text { minggu }\end{array}$ & $\begin{array}{l}\text { Adanya biogas } \\
\text { peternakan kini } \\
\text { hanya membeli } \\
\text { tabung ukuran 3 kg } \\
\text { satu kali dalam } \\
\text { sebulan }\end{array}$ \\
\hline 2 & $\begin{array}{l}\text { Tabung 15 kg } \\
\text { hanya bisa } \\
\text { digunakan kurang } \\
\text { lebih 1 bulan }\end{array}$ & $\begin{array}{l}\text { Adanya biogas } \\
\text { peternak kini } \\
\text { beraling dari tabung } \\
15 \text { kg ketabung 3 kg, } \\
\text { ituun sebagai } \\
\text { cadangan apabila } \\
\text { kegiatan masak- } \\
\text { memasak lebih } \\
\text { banyak. }\end{array}$ \\
\hline
\end{tabular}

Tabel 2. Biaya yang dapat dihemat peternak setelah menggunakan Biogas

\begin{tabular}{|c|c|c|}
\hline$\overline{\mathbf{N}}$ & $\begin{array}{l}\text { Biaya Penggunaan } \\
\text { gas LPG }\end{array}$ & $\begin{array}{l}\text { Biaya yang dapat } \\
\text { Dihemat se telah } \\
\text { Menggunakan BIOGAS }\end{array}$ \\
\hline 1 & $\begin{array}{l}\text { Tabung LPG } 3 \mathrm{~kg}= \\
\text { Rp } 17.000,- \text { dalam satu } \\
\text { bulan peternak dapat } \\
\text { menggunakan hiingga } \\
3 \text { tabung LPG ukurang } \\
3 \mathrm{~kg}, \text { jadi } 3 \times \mathrm{Rp} \\
17.000,-=\operatorname{Rp} 51.000,-\end{array}$ & $\begin{array}{l}\text { Dengan penggunaan } \\
\text { biogas peternak dapat } \\
\text { menghemat biaya LPG } \\
\text { sebesar Rp 34.000,- } \\
\text { setiap bulannya. Dalam } \\
\text { satu tahun peternak dapat } \\
\text { menghemat biaya = Rp } \\
\text { 34.000,- x } 12=\mathrm{Rp} \\
\text { 408.000,-/tahun }\end{array}$ \\
\hline 2 & $\begin{array}{l}\text { Tabung LPG } 15 \mathrm{~kg}= \\
\text { Rp 110.000,-/bulan }\end{array}$ & $\begin{array}{l}\text { Dengan menggunakan } \\
\text { biogas peternak kini } \\
\text { beralih dari tabung } 15 \mathrm{~kg} \\
\mathrm{ke} 3 \mathrm{~kg} \text { dan peternak } \\
\text { mampu menghemat biaya } \\
\text { LPG sebesar Rp 93.000,-- } \\
\text { setiap bulannya. Dalam } \\
\text { satu tahun peternak dapat } \\
\text { menghemat biaya = Rp } \\
\text { 93.000,- x } 12=\mathrm{Rp} \\
\text { 1.116.000,-/tahun }\end{array}$ \\
\hline
\end{tabular}

Penggunaan biogas pada peternak sangat membantu, dimana peternak menghemat biaya pengeluaran rumah tangga khususnya untuk keperluan BBM. Selain itu, ditemukan pula fakta bahwa sebaik apapun suatu teknologi peternak tidak mampu meninggalkan kebiasaan lama yaitu tetap menggunaan GAS LPG dengan alas an bahwa dengan menggunakan LPG masakan akan lebih cepat matang dan lebih praktis. Oleh karena itu, sebagai tambahan dari kegiatan ini bahwa penggunaan BIOGAS belum mampu menggantikan kedudukan LPG, namun biogas merupakan teknologi penunjang kegiatan peternak yang mampu medampingan LPG. Secara garis besarnya bahwa biogas merupakan Bahan Bakar Alternatif yang mudah diperoleh dan sekaligus menjaga kelestarian lingkungan.

\section{Pengolahan Pupuk Organik}

1. Urin yang ditelah dikumpulkan menggunakan wadah khusus, dicampur menggunakan air kelapa, tetes tebu, campuran rempah rempah berupa lengkuas, jahu dan temu lawak.

2. Setelah bahan tercampur bahan-bahan terbut didiamkan selama kurang lebih 15 hari.

3. Setelah itu diperoleh hasil fermentasi biourin.

4. Biourin yang telah jadi disimpan dalam kemasan khusus da kemudian diberi label.

\section{SIMPULAN}

Berdasarkan kegiatan yang telah dilaksanakan diperoleh kesimpulan bahwa:

1. Butuh waktu dua sampai dengan 3 minggu cacing mulai bertelur dan menhasilkan jumlah cacing dua kali lipat dari indukan sebelumnya. Setiap 3 minggu sekali dilakukan pemannenan 
dengan meisahkan cacing yang dewasa dengan anakan cacing.

2. Penggunaan biogas pada peternak sangat membantu, dimana peternak menghemat biaya pengeluaran rumah tangga khususnya untuk keperluan BBM. Selain itu, ditemukan pula fakta bahwa sebaik apapun suatu teknologi peternak tidak mampu meninggalkan kebiasaan lama yaitu tetap menggunaan GAS LPG dengan alas an bahwa dengan menggunakan LPG masakan akan lebih cepat matang dan lebih praktis.

3. Urin ternak yang diolah dengan baik akan memberikan keuntungan yang besar karena dapat dijadikan pupuk organik

\section{DAFTAR PUSTAKA}

Bambang Sutopo Hadi. 2013. Manfaata Urin Untuk Pupuk Cair. www.Google.com diakses 12 Oktober 2013.

Sri Dwiastuti. 2013. kajian tentang kontribusi cacing tanah dan perannya terhadap lingkungan kaitannya dengan kualitas tanah. Prodi P.Biologi Jurusan PMIPA FKIP Universitas Sebelas Maret.

Sugiharto, Ahmad Muhammad dan Windarti. 2013. kelimpahan dan biomassa cacing tanah pada lahan ruang terbuka hijau (rth) dalam kampus universitas riau, Pekanbaru.

Topngawi. 2013. Urin Sapi Untuk Pupuk. www.google.com. Diakses 23 Oktober 2013

Yusriadi, 2011. Faktor-Faktor yang Mempengaruhi Adopsi Perternak Sapi Perah tentang Teknologi Biogas di Kabupaten Enrekang, Sulawesi Selatan [tesis]. Bogor 2011: Program Pascasarjana, Institut Pertanian Bogor. 